\title{
O DIREITO A EDUCAÇÃO E A UTILIZAÇÃO DA TECNOLOGIA SOCIAL PARA A CONSTRUÇÃO DO CONHECIMENTO NO PROCESSO DE APRENDIZAGEM, INCLUSÃO E CAPACITAÇÃO DE JOVENS E ADULTOS
}

\author{
THE RIGHT TO EDUCATION AND THE USE OF SOCIAL TECHNOLOGY FOR THE \\ CONSTRUCTION OF KNOWLEDGE IN THE LEARNING, INCLUSION AND \\ TRAINING PROCESS OF YOUNG PEOPLE AND ADULTS
}

\begin{abstract}
Vinícius Samôr de Lacerda ${ }^{\mathrm{I}}$
RESUMO: A educação faz parte do rol de direitos humanos assegurados pela Declaração dos Direitos do Homem de 1948. Apesar do esforço das instituições de ensino e dos profissionais da educação, no Brasil, a maioria de nossos alunos deixam as salas de aula como um grande déficit de conhecimento e em seu processo de aprendizagem, o que vem influenciar na vida pessoal e profissional destes. Neste contexto, a tecnologia social pode diminuir ou eliminar o déficit de conhecimento e aprendizagem, assim como, a capacitação de jovens e adultos. O objetivo desta pesquisa é de verificar qual a importância da tecnologia social para a construção do conhecimento, no processo de aprendizagem e na capacitação de jovens e adultos. A temática é importante porque a utilização das tecnologias sociais para a capacitação profissional de jovens e adultos pode modificar a realidade socioeconômica destes. O método hipotético-dedutivo, neste contexto, oferece os meios de construir, metodologicamente, a análise do tema desta pesquisa e a formação de uma conjectura para responder ao problema inicialmente posto. A problemática desta pesquisa é: Qual a importância da utilização da tecnologia social para a construção do conhecimento, aprendizagem e capacitação de jovens e adultos?
\end{abstract}

PALAVRAS- CHAVE: Direitos Humanos. Tecnologia Social. Conhecimento. Aprendizagem. Capacitação Profissional.

ABSTRACT: Education is part of the list of human rights ensured by the 1948 Declaration of Human Rights. Despite the efforts of educational institutions and education professionals, in Brazil, most of our students leave the classrooms as a great lack of knowledge and in their learning process, which influences their personal and professional lives. In this context, social technology can reduce or eliminate the knowledge and learning deficit, as well as the training of young people and adults. The objective of this research is to verify the importance of social technology for the construction of knowledge, in the learning process and in the training of young people and adults. The theme is important because the use of social technologies for the professional training of young people and adults can change their socioeconomic reality. The hypothetical-deductive method, in this context, offers the means to construct, methodologically, the analysis of the theme of this research and the formation of a conjecture to answer the problem initially posed. The problem of this research is:

\footnotetext{
${ }^{1}$ Licenciado em Filosofia, pela Faculdade Mozarteum de São Paulo, bacharel em Teologia, Faculdade Entre Rios do Piauí. Pós-Graduado em Políticas Públicas, Gestão e Serviços Sociais, Universidade Candido Mendes. Mestrando em Tecnologias Emergentes em Educação, MUST UNIVERSITY. E-mail: vinicius7099@gmail.com.
} 
What is the importance of using social technology for the construction of knowledge, learning and training for young people and adults?

KEYWORDS: Human Rights. Social Technology. Knowledge. Learning. Professional Training.

\section{INTRODUÇÃO}

Apesar do esforço das instituições de ensino e dos profissionais da educação, no Brasil, a maioria de nossos alunos deixam as salas de aula como um grande déficit de conhecimento e em seu processo de aprendizagem, o que vem influenciar na vida pessoal e profissional destes.

Além do mais, o alunado, ao completar os estudos e saírem das instituições de ensino, carrega consigo a necessidade de se profissionalizar para galgarem um lugar no mercado de trabalho. Contudo, o nosso sistema de ensino é desprovido de mecanismos que possam auxiliar os recémformados em sua capacitação profissional.

Neste contexto, a tecnologia social pode diminuir ou eliminar o déficit de conhecimento e aprendizagem, assim como, possibilitar a capacitação de jovens e adultos para o desenvolvimento intelectual e profissional destes indivíduos trazendo melhores perspectivas para o futuro.

O objetivo desta pesquisa é de verificar qual a importância da tecnologia social para a construção do conhecimento, no processo de aprendizagem e na capacitação de jovens e adultos. A temática é importante porque a utilização da tecnologia social para a capacitação profissional de jovens e adultos pode modificar a realidade socioeconômica destes.

Esta pesquisa é básica, pois objetiva gerar conhecimentos novos para avanço da ciência sem aplicação prática prevista. Além do mais, esta é qualitativa, pois considera que existe uma relação entre o mundo e o sujeito que não pode ser traduzida em números.

Além disto, esta pesquisa também é exploratória, já que objetiva proporcionar maior familiaridade com um problema; envolve levantamento bibliográfico e análise de exemplos. Além do mais, ela é uma pesquisa bibliográfica elaborada a partir de material já publicado, como livros, artigos, periódicos, Internet.

O método hipotético-dedutivo, neste contexto, oferece os meios de construir, metodologicamente, a análise do tema desta pesquisa e a formação de uma conjectura para responder ao problema inicialmente posto. A problemática desta pesquisa é: Qual a importância da utilização da tecnologia social para a construção do conhecimento, aprendizagem e capacitação de jovens e adultos? 


\title{
2.I A UTILIZAÇÃO DA TECNOLOGIA SOCIAL PARA A DIMINUIÇÃO DO DÉFICIT DE APRENDIZAGEM.
}

Após o fim do regime militar, o Brasil passou pelo processo de redemocratização brasileira e teve como principal símbolo a formulação de nossa Constituição Federal no ano de 1988, conhecida como constituição cidadã, esta que trouxe a baila uma série de direitos sociais, inclusive o direito a educação, conforme o seu Art. 6ㅇ․

As questões de direitos humanos estão presentes em nosso cotidiano. Em uma sociedade em constante transformação é imprescindível atenção para que estes não sejam desrespeitados, pois são essenciais para os indivíduos, como é o caso da educação. Segundo Sacavino (2008, p.4),

\begin{abstract}
A problemática dos Direitos Humanos é um dos componentes fundamentais das sociedades atuais. Do plano internacional ao local, das questões globais às da vida cotidiana, os Direitos Humanos atravessam nossas preocupações, buscas, projetos e sonhos. Afirmados ou negados, exaltados ou violados, eles fazem parte da nossa vida pessoal e coletiva. Além disso, um discurso incisivo e persistente defende fortemente a importância dos Direitos Humanos se queremos construir verdadeiras democracias.
\end{abstract}

Após o fim do regime militar, o Brasil passou pelo processo de redemocratização brasileira e teve como principal símbolo a formulação de nossa Constituição Federal no ano de 1988, conhecida como constituição cidadã, esta que trouxe a baila uma série de direitos sociais, no seu Art. 6o, como o da educação. Segundo Candau (1999, p.3),

$\mathrm{Na}$ América Latina as experiências de educação em direitos humanos têm se multiplicado, principalmente a partir da década de 8o. No entanto, esta preocupação se desenvolveu de forma heterogênea nos diferentes países do continente, desenhando trajetórias diversas, sempre intimamente articuladas aos processos político-sociais vividos nos diferentes contextos.

No Art. 26을 da Declaração Universal dos Direitos Humanos de 1948 afirma que,

Toda a pessoa tem direito à educação. A educação deve ser gratuita, pelo menos a correspondente ao ensino elementar fundamental. O ensino elementar é obrigatório. O ensino técnico e profissional dever ser generalizado; o acesso aos estudos superiores deve estar aberto a todos em plena igualdade, em função do seu mérito.

A educação tem primordial importância para o desenvolvimento da personalidade, liberdade, capacidade intelectual do ser humano. Ainda no Art. 260 desta Declaração se explana que: "A educação deve visar à plena expansão da personalidade humana e ao reforço dos direitos do Homem e das liberdades fundamentais e deve favorecer a compreensão, a tolerância e a amizade entre todas as nações e todos os grupos raciais ou religiosos, bem como o desenvolvimento das atividades das Nações Unidas para a manutenção da paz". 
A tecnologia social é uma via cujo objetivo é solucionar ou minimizar problemas sociais em determinadas localidades e que podem influenciar de forma positiva na vida dos cidadãos. Segundo Oliveira (2012), este é uma alternativa à tecnologia convencional, com o objetivo de solucionar problemas sociais arraigados em determinadas comunidades pobres e um destes é o déficit de aprendizagem nas salas de aula.

O aprendizado pela via da tecnologia social ocorre quando os alunos internalizam conceitos, valores e normas sociais ensinadas, não só em sala de aula, mas no cotidiano. Segundo Longhi (2013), a aprendizagem é produzida a partir da capacidade do indivíduo, integrante de sucessivas gerações (individual e coletivamente), de se apropriar de novos comportamentos que, de forma paulatina, incorpora aos demais conteúdos socioculturais da espécie.

O conceito de aprendizagem está, muitas vezes, relacionado à educação e viceversa. Dessa forma, a aprendizagem social é vista como instrumento de desenvolvimento evolutivo, desempenhando importante papel na aprendizagem dos próprios indivíduos que constituem as sociedades (Longhi, 2013).

Ao sistema escolar é atribuída à função de proporcionar a estes alunos um bom aprendizado. Sendo assim, na visão de Habernas (1987 apud Longhi, 2013), a aprendizagem promove o aumento da autonomia, o que possibilita novas formas de pensar e agir e, isso se incorpora as estruturas cognitivas humanas.

Neste contexto, o processo de aprendizado do aluno em sala de aula se dá pela reprodução do conteúdo passado por meio de exercícios e testes. Contudo, segundo Santos (2013), essa prática mostrou-se ineficaz, pois a reprodução correta poderia ser apenas uma simples indicação de que o aluno aprendeu a reproduzir, mas não aprendeu o conteúdo.

A baixa produtividade no processo de aprendizagem de alunos não é só de responsabilidade das instituições de ensino e de seus colaboradores, mas do próprio Estado que deve dá condições necessárias para que este aconteça efetivamente. Neste sentido, ainda Paro (2013) explica que se faz mister um acompanhamento constante do trabalho escolar, garantindo um bom produto pela garantia de um bom processo.

Mesmo sem o suporte necessário pelo Estado, os professores procuram manter o objetivo de proporcionar a estes alunos um aprendizado de qualidade. Segundo Tedesco (2013), há uma unidade entre os professores, que os objetivos são comuns, que tem os mesmos anseios quanto à educação e o alcance da aprendizagem.

Além do mais, não é possível para os professores atuar no seio da escola e está alheio ao processo de aprendizado destes alunos. Segundo Domingo apud Libâneo (2013), pois a responsabilidade de ensinar e colaborar para o aprendizado dos alunos é uma prática humana que compromete moralmente quem a realiza. 
O processo de aprendizado destes alunos, pela via da tecnologia social, em sala de aula é consequência de uma vontade interna a estes. Segundo Almeida et al (2013), os motivos humanos para aprender qualquer coisa são profundamente interiores. $\mathrm{O}$ aluno deseja aprender quando há em si motivos profundamente humanos que desencadeiem tais aprendizagens.

A aprendizagem escolar depende, basicamente, dos motivos intrínsecos: um aluno aprende melhor e mais depressa quando sente-se querida, está segura de si e é tratada como um ser singular [...]. Se a tarefa escolar atender aos seus impulsos para a exploração e a descoberta, se o tédio e a monotonia forem banidos da escola, se o professor, além de falar, souber ouvir e se propiciar experiências diversas, a aprendizagem infantil será melhor, mais rápida e mais persistente (Rodrigues, 2013).

Além da vontade interna do aluno, o processo de aprendizagem pela via da tecnologia social pode ser facilitado por meio da criação de laços entre este, os seus pares e o professor. Neste sentido, é preciso que o aluno esteja adaptado ao ambiente no qual está inserido. Segundo Pimenta (2013) entende que toda aprendizagem está impregnada de afetividade, já que ocorre a partir das interações sociais, num processo vinculador.

No processo de aprendizagem, pela via da tecnologia social, além disto, há a preocupação em que o aluno aprenda corretamente os conteúdos e dali saia com conhecimento suficiente para compreender a sociedade em que vive. Segundo Bock (2013), é necessário que o aluno aprenda a aprender corretamente, ainda que "corretamente" assuma, na prática, sentidos diferentes para as diferentes faixas etárias.

O processo de aprendizagem a partir de experiências vividas promove, por fim, o amadurecimento destes alunos. Segundo Stenberg (2013), os esforços relacionados ao desenvolvimento cognitivo buscam compreender como as habilidades mentais surgem e modificamse em face da maturação biológica e da experiência ou aprendizagem.

Nem sempre o processo de aprendizagem ocorre de forma eficiente. Não poucos os alunos que saem das salas de aula com pouco conhecimento e prejudicados no processo de aprendizagem devido, por exemplo, as péssimas condições de nossas escolas e por isso a utilização da tecnologia social voltada a corrigir ou minimizar estas imperfeições é de primordial importância.

\subsection{A EDUCAÇÃO E A NECESSIDADE DE CAPACITAR OS JOVENS PARA O MERCADO DE TRABALHO PELA VIA DA TECNOLOGIA SOCIAL.}

A educação de jovens e adultos no Brasil sempre foi marcada por movimentos ou iniciativas individuais de grupos, órgãos públicos e privados ou pesquisadores decididos a enfrentar o problema da existência de uma enorme população que não tem oportunidade de se capacitar profissionalmente. Segundo Callavitta e Arruda (2014), 
É importante tentar descobrir uma forma resolver os problemas que levam tantos jovens a desistirem de estudar, e saber o que os levam a procurar a escola novamente, mais tarde. Isso é um trabalho grande, que envolve o Ministério da Educação, Secretarias Estaduais e Municipais de Educação, gestores e, é claro, os professores também, que precisam prepararse para essa realidade.

A problemática educacional no Brasil está marcada pela exclusão de camadas populares da sociedade que vem interditando a inúmeros cidadãos a possibilidade de acesso a capacitação profissional, à língua e a um universo de saberes produzidos nas diferentes áreas do conhecimento. Segundo Haddad e Pierro (200o),

Dentre os fatores de produção social do analfabetismo mediados pelo sistema escolar, devem ser considerados primeiramente o acesso e a permanência na escola durante a infância e adolescência que, ainda hoje, não estão assegurados a parcelas expressivas da população, com um diferencial negativo para os meninos e rapazes em comparação com as meninas e moças .

Para além da necessidade de escolarização fundamental, a perspectiva da capacitação profissional como patamar mínimo para a qualificação pessoal e profissional do sujeito, é a condição para o acesso aos diferentes espaços culturais e elemento possibilitador de reflexão e posicionamento político e autônomo. Segundo Sales (2010),

Tornou-se imprescindível uma educação continuada para que os indivíduos, segundo os discursos de muitos autores, mantenham-se em níveis crescentes de empregabilidade e/ou laboralidade. Com efeito, constata-se no contexto brasileiro a veiculação de novas legislações referentes à educação como um todo e, em específico, sobre a educação profissional.

A capacitação profissional de jovens e adultos por vias de tecnologia social é um desafio, não só para administradores governamentais, universidades, professores, como também para toda a sociedade e o próprio aluno. Sendo assim, a sua realização depende do esforço conjuntos dos variados setores sociais. Segundo Sales (2010),

Considera-se que uma educação profissional adequada deve propiciar o crescimento do aluno através de um processo socialização, inserção social e qualificação para o trabalho, envolvendo apropriação de saberes relativo à ciência, as técnicas, as tecnologias e às múltiplas culturas.

As bases do conhecimento sistematizado, neste sentido, deverão estar em seus aspectos sócioeconômico-político-culturais, visando à construção da consciência crítica e reflexiva, onde as capacidades, atitudes e valores sejam necessários para que as pessoas melhorem a qualidade de vida e continuem aprendendo, tendo uma vida justa e digna. Segundo Gonçalves e Fartes (2010),

Essa preocupação justifica-se pelo fato de que as características da sociedade contemporânea, marcada pelas contradições entre o avanço tecnológico e científico por um lado, e o desemprego, a instabilidade e precariedade no trabalho, por outro, indicam a necessidade crescente de qualificação do trabalhador, o que significa dizer que, se já não bastavam os programas de alfabetização de jovens e adultos, como tradicionalmente se fazia no Brasil, há meio século atrás, agora exige-se, além 
de capacidade geral e específica, preparação para o trabalho para perceber oportunidades e utilizá-las.

No processo de transformações pelas quais o mercado de trabalho tem passado recentemente, os jovens e adultos, candidatos às vagas de emprego, são elementos fundamentais do processo produtivo. Estes se deparam com a necessidade de constante adaptação e reciclagem dos conhecimentos e habilidades adquiridos. Segundo Gonçalves e Fartes (20ı),

Isto significa afirmar que a preparação do trabalhador não deve corresponder mais à antiga técnica de disciplinamento da força de trabalho, como a existente na estrutura anterior, mas promover uma formação que possibilite às pessoas transformarem as informações, acessadas por meio das diversas tecnologias, em conhecimentos vivos e significativos. Conhecimentos vinculados a uma nova condição humana, que possam não somente capacitar para o desempenho de uma função, mas, sobretudo, desenvolver nos sujeitos a capacidade de se envolver e participar em novas práticas sociais, políticas e culturais.

As principais exigências são a maior capacidade de autoaprendizagem, compreensão de processos, capacidade de observação, interpretação e tomada de decisões, assim como avaliação de resultados. Constituem requisitos, ainda, o domínio da linguagem técnica, a capacidade de comunicação oral e escrita, a disposição e habilidade para trabalhos em grupo, a polivalência cognitiva e a versatilidade funcional no ambiente de trabalho. Segundo PROEJA (2007),

Diversas outras ações estão em andamento para a consolidação desse projeto educacional que tem como fundamento a integração entre trabalho, ciência, técnica, tecnologia, humanismo e cultura geral com a finalidade de contribuir para o enriquecimento científico, cultural, polí- tico e profissional como condições necessárias para o efetivo exercício da cidadania.

A qualificação profissional de jovens e adultos, por vias da tecnologia social, neste contexto, amplia fundamentalmente a possibilidade de manter-se empregado e, ainda, permite aos candidatos às vagas de emprego, a busca futura por cargos que o remunerem de forma condizente à sua nova capacidade produtiva. Além disto, a valorização de suas habilidades faz com que seu poder de negociação frente aos empregadores se eleve, influenciando tanto no momento da contratação quanto na decisão salarial. Segundo PROEJA (2007),

Diversos outros planos estão em andamento: qualificação de profissionais através de cursos de extensão; articulação com programas de pós-graduação em Educação para abertura de linhas de pesquisa [...] e produção de material educativo referencial para a elaboração de material didático.

Ademais, a qualificação profissional de jovens e adultos, por vias da tecnologia social, refletese positivamente na autoestima dos indivíduos, assim como em sua preocupação com as questões políticas, econômicas e sociais, uma vez que as mesmas são percebidas como elementos que afetam o ambiente trabalhista. Rummert e De Vargas (s,d),

Esse modo de focalizar a questão nos remete a um objetivo fundamental no âmbito da Educação de Jovens e Adultos: contribuir para a incorporação daqueles que estão 
vivenciando diferentes mecanismos de exclusão, dentro de um processo de construção de uma sociedade não-excludente e solidária.

Não obstante as inúmeras definições para desenvolvimento econômico tem-se o mesmo como reflexo da qualificação profissional de jovens e adultos, por vias da tecnologia social, uma vez que os benefícios oriundos do crescimento são revertidos a toda sociedade sob a forma de redução das desigualdades políticas, econômicas e sociais, assim como melhorias na qualidade de vida dos indivíduos. Rummert e De Vargas $(s, d)$,

Entendemos que uma atuação ampla e efetiva, no âmbito de Educação de Jovens e
Adultos se apresenta como fundamental em nosso país, desde que se pretenda
construir uma sociedade que integre social, política, cultural e economicamente a
totalidade da população e não apenas parte dela, como é característica do projeto
neoliberal. Entretanto, a educação só pode ser compreendida como parte essencial
de um processo com múltiplas determinações e não como chave mágica que
promove a inclusão na sociedade de mercado, em que a competitividade e o
individualismo se impõem como valores supremos.

Uma vez compreendido a importância da educação de jovens e adultos, por vias da tecnologia social, assim como, a sua qualificação profissional. No próximo capítulo deste artigo, explanaremos acerca da importância da produção do conhecimento para a inclusão de jovens e adultos no mercado de trabalho.

\subsection{A PRODUÇÃO DO CONHECIMENTO PARA A INCLUSÃO DE JOVENS NO MERCADO DE TRABALHO.}

O conhecimento é a maior riqueza que um jovem pode adquirir ao longo de sua vida pessoal e dentro da sala de aula. Segundo Santos (2013), a educação deve formar os alunos para se tornarem cidadãos críticos e que valorize cada vez mais o conhecimento acumulado durante a vida. Segundo Axt e Maraschin (s.d),

O conhecimento é tido como uma substância, ele pode ser acumulado, guardado, constituindo um acervo público ou privado; pode escalonar as pessoas, valorizandoas de acordo com o grau de conhecimentos que possuírem; pode converter-se em mercadoria, ser vendido, ser transmitido.

$\mathrm{Na}$ sala de aula, o jovem adquire conhecimento e desenvolve habilidades, por vias da tecnologia social, no convívio com os seus pares e pelas atividades realizadas. Ainda Santos (2013) explica que o conhecimento vem a partir de consultas em livros, leituras, tomada de notas, sínteses, conclusões, interpretação de gráficos e dados.

Os professores, neste contexto, são detentores de um conhecimento limitado, mas que pretendem situar os jovens na sociedade em que vivem. Segundo Weisz (2002), o que está à disposição dos professores hoje é um corpo de conhecimentos que, se não dá conta de tudo, pelo menos ilumina os processos através dos quais os alunos conseguem ou não aprender certos conteúdo. 
A produção do conhecimento em sala de aula, por vias da tecnologia social, se dá pela interação tridimensional entre professor-jovem-conteúdo. Segundo Dolzan e Rego (2013), a ideia de mediação na escola coloca que a construção do conhecimento está diretamente relacionada à interação entre sujeito/sujeito e sujeito/objeto.

A relação entre o jovem e o professor é primordial, pois é a partir da confiança mútua entre estes que as possíveis dificuldades na construção do conhecimento são diminuídas ou eliminadas. Segundo Baibich-faria e Meneguetto (2013), esta postura favorece o clima de confiança, permitindo que o aluno possa participar mais ativamente na construção do próprio conhecimento.

Os jovens produzem o conhecimento quando selecionam e absorvem as informações dandolhes significado com o auxílio dos professores em sala de aula. Segundo Davis e Grosbaum (2013), a interação entre professores e alunos em torno do conhecimento, que constitui a dinâmica de sala de aula, decorre da forma como o professor vê os processos de ensino e de aprendizagem.

O jovem é um ser social e, neste sentido, constrói o seu conhecimento por meio de experiências vividas no seu dia a dia, no seio de sua família e na escola onde ele aperfeiçoa este conhecimento. Segundo Pimenta (2013), este pensar reflete o aluno enquanto ser histórico, ou seja, o pensar do aluno é condicionado pelas possibilidades e limitações pessoais e no contexto em que atua.

O professor, neste sentido, é peça fundamental para que os jovens construam o conhecimento que necessitam para o seu desenvolvimento escolar. Segundo Ferreira (2013), este pode reconhecer quando um processo de construção do conhecimento está sendo efetivo, quando o mesmo se permite sentir o processo.

Além da produção do conhecimento progressivo na sala de aula, por meio dos conteúdos oferecidos pelas instituições, por vias da tecnologia social, o jovem aprende a conhecer a si mesmo em decorrência de suas interações com os demais. Nesse sentido, Fonseca et al (2013) destaca a importância do outro no processo não só de construção do conhecimento, mas também de constituição do próprio sujeito e de suas formas de agir.

\section{CONCLUSÃO}

Esta pesquisa tinha o objetivo de verificar a importância da tecnologia social para a construção do conhecimento no processo de aprendizagem e na capacitação de jovens e adultos. Para isso, utilizamos o método hipotético dedutivo por meio de uma pesquisa bibliográfica de cunho exploratório.

A educação é um direito inerente à pessoa humana e está assegurado na Declaração de Direitos do Homem, assim como, no bojo da Constituição Federal de 1988. Portanto, é direito dos brasileiros ter uma educação de qualidade e capacitação profissional. 
Quanto às respostas obtidas nesta pesquisa, verifica-se que a tecnologia social pode ser uma grande aliada para a complementação da educação de jovens e adultos que, na maioria das vezes, saem das instituições de ensino com déficit de aprendizagem, pouco conhecimento acerca dos conteúdos transmitidos em sala de aula.

Além do mais, a tecnologia social voltada para a capacitação de jovens e alunos pode proporcionar a estas melhores perspectivas de vida, pois permite a estes condições intelectuais de galgarem um emprego no mercado de trabalho cada vez mais competitivo.

\section{REFERÊNCIAS}

ALMEIDA, Maria Amelia;MENDES, Enicéia Gonçalves; HAYASHI, Maria Cristina Piumbato Innocentini. IV Temas em educação especial. Brasília/DF: CAPES- PROESP, 2013.

AXT, Margaret; MARASCHIN, Cleci. Conhecimento, s.d.

BAIBICH-FARIA, Tânia Maria; MENEGUETTO, Francis Kanashiro. Metodologia do ensino superior ou ética da ação do Professor. Curitiba: UFPR/GT: Didática, 2013.

BOCK, A.; al. Psicologias: uma introdução ao estudo da Psicologia. $7^{\underline{a}}$ ed. São Paulo: Saraiva, 2013.

CANDAU, Vera Maria, et al. Oficinas Pedagógicas de Direitos Humanos. Petrópolis: Vozes, 1995.

COLAVITTO, Nathalia Bedran; ARRUDA, Aparecida Luvizotto Medina Martins.

Educação de Jovens e Adultos (eja): A Importância da Alfabetização, 2014.

DECLARAÇÃO UNIVERSAL DOS DIREITOS HUMANOS. Adotada e proclamada pela resolução 217 A (III) da Assembléia Geral das Nações Unidas em io de dezembro de 1948.

BRASIL. Constituição (1988). Constituição da República Federativa do Brasil. Brasília: Senado, I988. Disponível em: https://www.senado.gov.br/atividade/const/conı988/CONi988_05.10.1988/art_I44_.asp , Acessado em ig de outubro de 2018.

COUTINHO, Jamile Serra; OLIVEIRA, Vinicius. Qual a importância da mediação no processo de aprendizagem?, 2013.

DAVES, C.; GROSBAUM, M. W. Sucesso de todos, compromisso da escola. In: VIEIRA, S. L. (org.) Gestão da escola: Desafios a enfrentar. Rio de Janeiro, DP\&A, 2013.

DOLZAN, Cecilia: REGO, Tereza Cristina. Vygotski: uma perspectiva histórico-cultural da educação. Petrópolis: Vozes, 2013.

FONSECA, M.; OLIVEIRA, J.F. de; TOSCHI, M.S. As tendências da gestão na atual política educacional brasileira: autonomia ou controle? In: BITTAR, M. e OLIVEIRA, J.F (Org.). Gestão e políticas da educação. Rio de Janeiro, DP\&A editora, 2013.

FREITAS, H. C. L. Formação de Professores no Brasil: to anos de embates entre projetos de formação. Educação \& Sociedade, Campinas, v. 23, n. 8o, p. 137-168, 2013.

GONÇALVES; Maria de Cássia Passos Brandão; FARTES, Vera Lúcia Bueno. O trabalho docente na educação profissional de jovens e adultos, 2010.

HADDAD, Sérgio; PIERRO,Maria clara di. Aprendizagem de jovens e adultos avaliação da década da educação para todos, 2000. 
INSTITUTO DE TECNOLOGIA SOCIAL. ITS. Caderno tecnologia social: conhecimento e cidadania I: tecnologia social, 2007. LIBÂNEO, J. C. Didática. São Paulo: Cortez, 2013.

LONGHI, Armindo José. Ação educativa e agir comunicativo. Caçador: Unc caçador, 2013. OLIVEIRA, N.; SILVA, T. N. Inovação social e tecnologias sociais sustentáveis em relacionamentos intercooperativos: um estudo exploratório no Creditag- $R O$. Revista de Administração da UFSM, v. 5, n. 2, 2012.

PARO, V. H. Gestão escolar: democracia e qualidade de ensino. São Paulo: Ática, 2013. PIMENTA, S. G. (Org) Didática e formação de professores: percursos e perspectivas no Brasil e em Portugal. 4 ed. São Paulo: Cortez, 2013.

PROEJA. Programa nacional de integração da educação profissional com a educação básica na modalidade de educação de jovens e adultos, 2007.

SALES, Paula Elizabeth Nogueira. Políticas para a capacitação profissional de jovens: estudo sobre as relações entre as atividades teóricas e práticas em um programa de aprendizagem, 2010.

SANTOS, Elenir Souza. Trabalhando com alunos: subsídios e sugestões: o professor como mediador no processo ensino aprendizagem. Revista do Projeto Pedagógico; Revista Gestão Universitária, n. 40. Disponível em: Acesso em: I8 abr. 2013.

SACAVINO, Susana (org.). Educação em Direitos Humanos: temas, questões e propostas; Rio de Janeiro: DP\&Alli, 2008.

STERNBERG, R. J. Psicologia cognitiva. Porto Alegre: Artes Médicas, 2013.

TEDESCO, J. C. O novo pacto educativo: educação, competitividade e cidadania na sociedade moderna. Vila Nova de Gaia, Fundação Manoel Leão, 2013.

WEISZ, Telma. O diálogo entre o ensino e a aprendizagem. São Paulo: Ática, 2013. 